\title{
Todos queremos um ensino das ciências melhor
}

É SABIDO, POR SER täo LaRgamente puBlicitado nos órgãos de comunicação social, difundido por responsáveis governativos, comprovado por testes nacionais e internacionais, que o conhecimento em ciências em Portugal é fraco. A literacia científica dos nossos cidadãos, de vários grupos etários e graus diferenciados de habilitaçāo, é insuficiente. No entanto, o currículo abrange 0 ensino das ciências desde o $1^{\circ}$ ciclo até ao fim da escolaridade obrigatória, os programas que norteiam o trabalho dos professores estão repletos de informação, com propostas de experiências educativas interessantes, e há manuais escolares para todos os gostos.

Também é sabido que os nossos alunos não se interessam grandemente pela Ciência, fundamentalmente a Física e a Química, e a prova é a diminuição drástica da escolha de alguns cursos universitários nestas áreas (explicada com alguma ligeireza pela diminuição da natalidade que agora se começa a fazer sentir no nosso país). Não é por muita Ciência se ensinar que se aprende meIhor. Não é por se exigir quantidade que a qualidade nasce.

É sabido, igualmente, que a nossa tradição no ensino das ciências é disciplinar e compartimentada, baseada na repetição de conteúdos, desfasada, muitas vezes, da realidade dos alunos e, também por isso, desmotivante. Perguntese a um conjunto de alunos do $10^{\circ}$ ano da área das humanidades o que pensa que sabe de ciências, se gostou do ensino que teve na escolaridade básica, e o que é que mudava. Provavelmente as respostas estarão em sintonia com o que é sentido em geral. Mas se o questionário for feito a alunos da área das ciências, talvez as respostas não variem muito e o interesse pela área venha de outras experiências e não da escola. É curioso analisar-se o que Carl Sagan (1995) disse sobre a escola que teve:

Havia a memorização maquinal da tabela periódica dos elementos, alavancas e planos inclinados, a fotossintese das plantas verdes e a diferença entre a antracite e a hulha (...) Nas aulas laboratoriais do liceu havia uma resposta que deviamos dar e se não o conseguiamos tínhamos nota negativa. Não havia estimulo para nos debruçarmos sobre os nossos interesses, palpites ou erros conceptuais. No final dos manuais havia material que se podia considerar interessante, mas o ano acabava sempre antes de lá chegarmos. Encontravam-se livros maravilhosos sobre astronomia nas bibliotecas, por exemplo, mas não na sala de aula. As contas de dividir eram ensinadas como um conjunto de regras de um livro de cozinha (...) No liceu a extracção de raízes quadradas era-nos apresentada com veneração, como se fosse um método sagrado. Tudo o que tínhamos a fazer era recordar o que nos tinham mandado fazer. Dá a resposta certa e não te rales se não percebes o que estás a fazer. ( $p .12)$
Isto reporta-se ao princípio do século $X X$, num contexto bem diferente do nosso, os Estados Unidos da América, mas não seria preciso grande esforço para encontrarmos semelhanças com a escola que ainda temos em Portugal.

Talvez o ensino das ciências enferme, ainda hoje, de falta de desenvolvimento de raciocínio e tenha excesso de memorização. 0 que espantou mais na análise feita a partir dos resultados de testes nacionais e internacionais não foi a falta de conhecimentos dos nossos alunos, aí não estavam muito longe dos colegas de outros países, a surpresa foi a pouca capacidade de raciocínio, de adaptação a questões novas, e de flexibilidade do pensamento. Talvez a tónica deva estar no modo como se ensinam os conteúdos científicos, como se estimula a curiosidade dos nossos alunos, como se cativa para o deslumbramento dos fenómenos e para a sua explicação. Ensinar listas e listas de conteúdos, desligados entre si, "as ciências" vistas como disciplinas que é preciso saber para passar de ano, mais do que deslumbrar os alunos com a Ciência que nos ajuda a entender o mundo, assim tem sido o ensino das ciências, de um modo geral, em Portugal. Sabemos, contudo, que há bons professores que nos marcam e nos despertam para determinadas profissões nessa área.

As orientações curriculares das Ciências Físicas e Naturais para o $3^{\circ}$ ciclo do ensino básico pretendem romper com

\footnotetext{
*Coordenadora da equipa que elaborou o documento sobre as competências específicas para as Ciências Fisicas e Naturais para o Ensino Básico e as Orientaçōes Curriculares para as Ciências Físicas e Naturais do $3^{\circ}$ ciclo do Ensino Básico (http://www.deb.min-edu.pt). Professora do Departamento de Educação da Faculdade de Ciências de Lisboa, cgalvao@fc.ul.pt
} 
essa visão e ajudar os professores a programar para os seus alunos aulas mais estimulantes e em sintonia com o que se entende hoje ser o conhecimento. Neste nivel etário, a compartimentação excessiva é mais negativa que benéfica. É no ensino básico, e desde muito cedo, que se podem captar as crianças para a procura de explicações, para o incentivo ao questionamento. Não se pretende que saltem da banheira, no $9^{\circ}$ ano, a gritar "Eureka", mas se forem estimulados para as explicaçōes científicas talvez o façam daqui a 20 anos. Carl Sagan começou a interessar-se por astronomia quando, aos 7 anos de idade, os pais o levaram a uma feira da Ciência a Nova lorque. Que pena a escola não ter estado na origem deste gosto! Mas pode estar. Acreditamos que pode fazer muito mais no estímulo pela aprendizagem, pela leitura, pela curiosidade de ver, de mexer e de saber mais. É isso que significa, também, aprender a aprender, que só é vazio se nada metermos lá dentro.

O ensino básico apresenta um desafio tremendo aos legisladores, a autores de programas e de manuais, aos professores. Tem de se ensinar o que se considera fundamental a todos os alunos para serem cidadãos esclarecidos e responsáveis, para serem bons profissionais nas áreas em que trabalham, para terem conhecimentos de modo a prosseguirem estudos. $E$ isso implica ensinar todos os alunos, isto é, dar oportunidade a todos de chegarem onde forem capazes sem os limitar à partida. Embora saibamos que nem todos conseguem chegar ao mesmo sítio, nem ao mesmo tempo, por razões diversas, de natureza cognitiva ou social. É isto que significa respeitar o ritmo de aprendizagem dos alunos, não é nivelar por baixo, não é exigir menos, é ter a paciência e o conhecimento para estimular uns e outros, os que andam depressa e merecem ser acompanhados ao ritmo da sua rapidez e os que andam devagar e merecem ser incentivados e puxados para chegarem mais longe. Os testes internacionais mostram-nos uma média onde encontramos bons alunos (e temos alguns excelentes) e muitos outros que não al- cançam o minimo. Há trabalho a desenvolver com todos eles.

A flexibilização dos programas não é ir ao "deus-dará", porque é obrigatório saber e saber bem. Ensinar é uma grande responsabilidade e ensinar bem é o dever de todos os professores. Nenhum programa os limita na sua competência, simplesmente há programas mais rígidos que os prendem e outros que os deixam criar, dentro de certos limites, 0 que consideram melhor para os seus alunos. O currículo, quer queiramos quer não, é o que os professores vivem com os seus alunos na sala de aula e na escola em geral, não é o que está escrito no papel. Mas, o papel pode ajudálos nessa definição se sugerir experiências educativas estimulantes para os alunos, se estas forem entendidas e experimentadas, se forem questionadas e discutidas com os colegas. É por isso que o programa agora apresentado para as Ciências Físicas e Naturais propõe 0 confronto de ideias entre as disciplinas de Ciências Naturais e de Ciências Físico-Quimicas, para quebrar a regra do isolamento e do desconhecimento do que se faz na sala ao lado. Pode dizerse que não é por estarem escritos lado a lado que os programas deixam de estar de costas voltadas. É verdade, mas se assim não estiverem organizados, a probabilidade de conhecer o que o colega professor das nossas turmas faz é menor e o diálogo possivel tem muito menos hipótese de acontecer. A entropia às vezes é necessária para abalar as convicções. Não se defende a compreensão no vazio dos factos, ou meIhor, defende-se que os conteúdos são fundamentais, o que se pede aos professores é que sejam discutidos com os colegas para que o que é trabalhado na sala de aula ou noutros espaços da escola seja compreendido e tenha sentido para os alunos. A ligação a outras disciplinas também é aconselhada, porque 0 conhecimento é global e as explicações que procuramos para entender as nossas interrogações sobre o mundo, não se confinam a uma determinada disciplina. Há cada vez mais quem defenda a ligação entre várias culturas (científica, humanista, artística). Então, para quê separar duas ciências tão afins no modo como olham para a natureza e a explicam? Dawkins (1998) refere que o poeta Keats estava contra Newton porque tinha destruido a beleza do arco íris ao explicá-lo. No entanto Keats "poderia ter sido um poeta ainda melhor se tivesse ido buscar à Ciência alguma da sua inspiração" (p. 46).

Os temas propostos no programa apresentado para o desenvolvimento das Ciências Físicas e Naturais no ensino básico podiam ser outros completamente diferentes, não é isso que é relevante, embora haja uma justificação conceptual subjacente. As orientações curriculares foram pensadas por ciclo e não por anos, para quebrar com a sequencialidade temática rígida, incompatível com uma adequação flexivel. No entanto, essa sequencialidade existe, porque tinha de haver um fio condutor, podia ser outro, mas foi este que foi escolhido. Pretende-se que, após terem compreendido conceitos relacionados com a estrutura e funcionamento do sistema Terra, os alunos sejam capazes de os aplicar em situações que contemplam a intervenção humana e a resolução de problemas daí resultantes, visando a sustentabilidade na Terra. Sendo assim, há uma complexidade e abstracção crescentes na exploração dos conteúdos, o que, se os professores assim entenderem, implica a exploração do tema Terra no espaço em primeiro lugar e de Viver melhor na Terra em último. 0 que importa é o modo como se sugere a exploração desses temas, a partir de questões, de problemas a que as actividades que se desenvolvem na aula têm de dar resposta. Além disso, o desenvolvimento dos temas tem explícita a ideia que para criar qualidade de vida, no sentido pessoal e colectivo, é indispensável a participação de todos. Alertar as crianças e os jovens para a importância do seu comportamento e intervenção na gestão dos recursos, torná-los sensiveis ao que se passa à sua volta, aprendendo a discutir e a dar argumentos que fundamentem a sua opinião, é educar para o ambiente e a sustentabilidade. Salvar a Terra da intervenção negativa da humanidade não é utopia, é hoje uma necessidade. 
No entanto, reconhecemos que há alguma dificuldade de organização e de compreensão do que é proposto, de acordo com conversas que temos tido com professores. No que diz respeito à organização, salientamos o que muitos professores já constataram que é, por exemplo, pouco o tempo reservado à área das ciências no $3^{\circ}$ ciclo. Seis blocos e meio a serem geridos pelas duas disciplinas exige um grande esforço e o sacrificio, por vezes, de estratégias de aula mais demoradas na sua consecução, como são, o planeamento e execução de actividades experimentais (não o receituário que se segue maquinalmente, muitas vezes sem se compreender objectivos nem discutir resultados), a concepção e realização de projectos, a discussão bem conseguida sobre temas controversos, o que vai contra o que pensamos que deve ser o ensino das ciências. A falta de tempos comuns para reunião de professores das duas disciplinas que leccionam a mesma turma é outro problema que os professores referem, assim como um único bloco de 90 minutos por semana com os alunos, ocasiona, em certas situaçōes, um intervalo pouco propício à aprendizagem dos assuntos. A possibilidade de desdobrar as turmas pode ajudar a diminuir este problema.

Quanto à dificuldade de compreender o que é proposto, há a registar alguns equivocos. A confusāo sobre o que é transversal faz com que em algumas escolas se separem completamente as disciplinas das áreas não disciplinares, pensando que só nestes últimos espaços é que os alunos desenvolvem as chamadas competências transversais. Uma vez que essas competências (de comunicação, de aprender a pensar e a estudar, de cooperação, de cidadania) se desenvolvem justamente em interacção com os conhecimentos, é preciso conceber as áreas nāo disciplinares em estreita ligação com as disciplinas e não como algo que se acrescenta. A área de projecto, por exemplo, não tem que ter projectos inventados para cumprir o curriculo, pode perfeitamente dar espaço ao desenvolvimento de projectos que os alunos concebem nas ciências, na geografia, na matemática, etc. Um bom planeamento evita atropelos e poupa esforços. Assim, talvez o tempo das ciências "se estique" um pouco.

Uma das críticas que têm sido feitas às orientações curriculares para as Ciências Físicas e Naturais para o $3^{\circ}$ ciclo do ensino básico, é que os conteúdos expressos não são ilustrativos em si mesmos do grau de profundidade, obrigando à leitura das experiências educativas. Mas isso foi propositado. Uns não podem ser vistos sem as outras. As experiências educativas que sugerimos tentam dar pistas aos professores sobre como fazer, estando implícitos a abrangência e o aprofundamento necessários a este nivel de escolaridade. Temos de confiar nos professores, nas suas competências como profissionais. Além disso, o não explicitarmos mais os conteúdos tem a intenção de o ensino das ciências não se ficar pelo produto da Ciência, que é importante, mas limitador daquilo que a Ciência é. O cepticismo, a dúvida, a argumentação só são possiveis de serem estimulados pelo confronto de perspectivas, pelo lidar com previsões e erros e não apenas com produtos científicos apresentados como verdades. A actividade experimental, a observação do que se passa à volta, a ligação ao ambiente, à tecnologia e à sociedade, o desenvolvimento de projectos, são perspectivas que estão subjacentes às propostas que fazemos, e que podem ser introduzidas nos currículos de ciências desde muito cedo.

Outro equívoco é que nada é obrigatório, o que pode ter consequências gravissimas se levado até ao extremo. 0 currículo é obrigatório, o que está escrito nos programas ou nas orientações curriculares, é para saber, o que é flexível é a sua gestão, o modo como os professores o adequam aos alunos e aos contextos. Por que é que em todas as escolas do país se há-de começar ao mesmo tempo, pelos mesmos assuntos e da mesma maneira? Os professores sempre tiveram autonomia para gerirem os currículos, o que se pede agora é que o façam de uma maneira mais concertada uns com os outros, que dêem sentido a essa gestão na escola onde trabaIham, mas no fim do $3^{\circ}$ ciclo do ensino básico todos os alunos têm de saber o que está determinado. Daqui decorre que é possivel fazer manuais escolares e avaliar os alunos, o que se pede é que tanto os manuais como a avaliação estejam em sintonia com o currículo. Deixamos porém um alerta, os manuais são material de trabalho para os alunos, não devem ser o recurso de formação do professor, além de que hoje em dia há que diversificar as fontes de informação; a internet, as bibliotecas de papel e electrónica, outros livros, são recursos que alunos e professores devem usar. Outro alerta é que exame não é sinónimo de avaliação. Há muitas outras formas possiveis de avaliar. Mesmo um exame pode ter uma perspectiva diferente da que conhecemos. A avaliação é outra componente do currículo que necessita muito de ser discutida e trabaIhada.

Temos consciência que este é um processo que está longe de estar acabado, e que pede bastante aos professores, principalmente porque exige uma mudança de perspectiva e isso é sempre o mais difícil. Os professores merecem o nosso apoio e respeito pelo esforço que Ihes é exigido, por isso estamos a desenvolver um conjunto de actividades de exploração de cada tema que os ajude na definição da extensão e profundidade dos conteúdos. Porque não basta demonstrar aos alunos que a ciência é divertida, é preciso que compreendam a beleza e utilidade das suas explicações e que sintam que vale a pena o esforço de a aprenderem.

\section{Referências}

Dawkins, R. (1998). Decompondo o arcoiris. Lisboa: Gradiva

Sagan, C. (1995). Um mundo infestado de demónios. Lisboa: Gradiva 


\section{Eur}

\section{European Journal of Inorganic Chemistry}

\section{Yourjournal}

First Impact Factor: 2.222

Rapid publication times especially for short communications

Now supported by ten national chemical societies (Belgium, France, Germany, Greece, Hungary - together with the Hungarian Academy of Sciences, Italy, The Netherlands, Portugal, Spain)

Authors' work exhibited on the cover

Attractive personal member subscription rates available;

see: www. EurJIC.com

More color

\section{European Journal of Inorganic Chemistry}

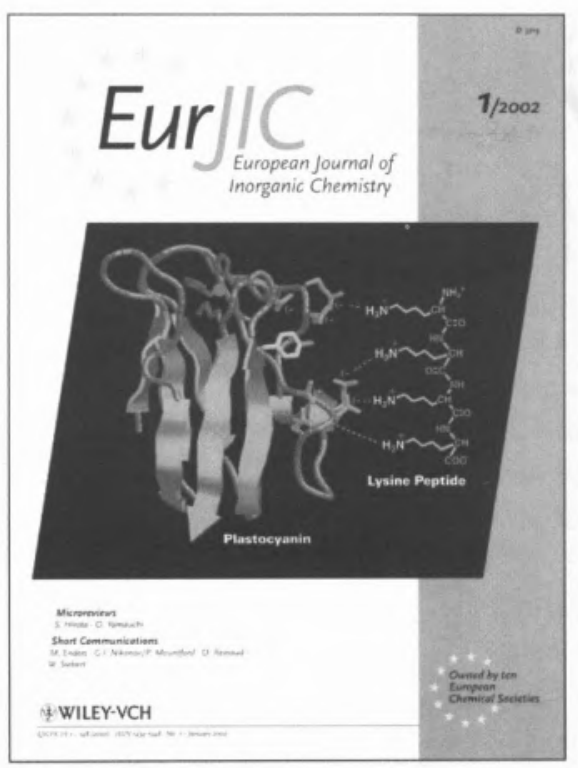

Wiley-VCH

200212 issues

ISSN Print 1434-1948

ISSN Electronic 1099-0682

The European Journal of Inorganic

Chemistry publishes full papers and

short communications on the

entire spectrum of inorganic and

organometallic chemistry. These

contributions are supplemented by

microreviews - introducing readers

to one specific area of an author's

research by means of a detailed

overview of one selected topic.

Senior Editor: Ivano Bertini (Italy)
Order Your Copy now:

Just copy, fill in and fax to: +49/(0)6201/606-172

\lrcorner Please send me a free sample print copy

\lrcorner Please enter our/my 2002 subscription to:

European Journal of Inorganic Chemistry

2002, ISSN Print 1434-1948 2002, ISSN Electronic 1099-0682

at the institutional rate*

$$
\begin{aligned}
& \text { print electronic } \\
& \lrcorner \text { Europe } J € 1868 \quad J € 1868 \\
& \lrcorner \text { Switzerland 」 } \mathrm{sFr} 3258 \text { J sFr } 3258 \\
& \lrcorner \text { All other } \\
& \text { countries JUS\$2308 JUS\$ } 2308 \\
& \text { print } \\
& \lrcorner \text { Europe }\lrcorner \in 218 \\
& \lrcorner \text { Switzerland }\lrcorner \text { sFr } 458 \\
& \lrcorner \text { All other } \\
& \text { countries JUS\$248 }
\end{aligned}
$$

Prices include postage and handling charges.

Please tick: $\square$ private $\square$ business

Name

Address

City/Postcode

Country

Membership-No.

Date/Signature

Please return this order to your local bookseller or to:

Customers in Germany, Austria and Switzerland:

Wiley-VCH Customer Service

P.O. Box 101161 ,

D-69451 Weinheim, Germany Phone: +49 (0) 6201-606147

Fax: +49 (0) 6201-606172 e-mail: subservice@wiley-vch.de

Customers in all other areas: John Wiley \& Sons, Ltd.

Journals Administration Department 1 Oldlands Way

Bognor Regis West Sussex, P022 9SA, England

Phone: + 44 (0) 1243-779 777

Fax: + 44 (0) 1243-843 232

e-mail:cs-journals@wiley.co.uk 